This is a self-archived version of an original article. This version may differ from the original in pagination and typographic details.

Author(s): Säilävaara, Jenny

Title: Long-Term Breastfeeding : The Embodied Experiences of Finnish Mothers

Year: 2020

Version: Accepted version (Final draft)

Copyright: @ 2019 The Nordic Association for Women's Studies and Gender Research

Rights: In Copyright

Rights url: http://rightsstatements.org/page//nC/1.0/?language=en

Please cite the original version:

Säilävaara, J. (2020). Long-Term Breastfeeding : The Embodied Experiences of Finnish Mothers. NORA : Nordic Journal of Feminist and Gender Research, 28(1), 43-55.

https://doi.org/10.1080/08038740.2019.1694581 
Jenny Säilävaara

University of Jyväskylä, Finland

jenny.w.sailavaara@jyu.fi

ORCID id: 0000-0001-8155-757X

\section{Long-Term Breastfeeding: The Embodied Experiences of Finnish Mothers}

\section{Introduction}

In Finland, breastfeeding at birth and in infancy is expected and highly recommended. The National Institute for Health and Welfare has set the goal of making Finland the leading country in breastfeeding in the coming years (Hakulinen \& Otronen 2017). The national recommendation is that mothers breastfeed exclusively for six months and continue until the child is at least twelve months old (THL 2016). Currently, Finnish mothers breastfeed their children for on average six to seven months, breastfeeding exclusively for the first two months (THL 2016). However, breastfeeding for over one year is not culturally expected, and Finnish statistics do not go beyond the baby's first year. In their article on British mothers, Newman and Williamson $(2018,230)$ suggest that long-term breastfeeding is 'nonnormative', and further that 'societal views about it are usually negative'. This article argues that the same cultural reticence also applies to Finland.

Along with the other Nordic states, Finland differs from countries that do not have long parental leave. In Finland, a mother typically stays at home for at least nine months, and after that period parents are entitled to care leave for up to three years. It is taken mostly by mothers and rarely by fathers (THL 2018). Despite this, when women work, they work fulltime, supported by the Finnish day-care system that functions relatively well, and where all children under the age of six are entitled to municipal day-care if their parents are working or studying. Mothers living in Finland also receive public healthcare at maternity clinics before and after the child is born. All this can have a positive effect on the initiation of breastfeeding, and its duration, compared to countries where mothers are required to return to work a few weeks after birth and/or have limited access to public healthcare. The welfare state then, enables longer-term breastfeeding, even if societal views of breastfeeding can be negative. 
Nonetheless, Finland also faces the challenges created by socio-economic differences. While a recent study revealed that a mother's education influences breastfeeding duration, it also found that income level, age, and belonging to an ethnic minority have an impact (Hakulinen \& Otronen 2017). Consequently, the article contributes to discussions about breastfeeding, difficulties in mothering, and the ways in which contemporary society attempts to control female bodies. Charlotte Faircloth has pointed out that while long-term breastfeeding mothers bring up the "pleasurable and joyful side of the breastfeeding relationship," it seems to be absent from discussions of "affect and policy" (Faircloth 2013: 356). This article thus explores the "emotional dimensions of breastfeeding" (Breengaard 2018, 326) as an embodied experience that can evoke both positive and negative emotions. My interest in embodiment stems from the notion of 'doing of breastfeeding,' which refers to the impact that 'social context and structural constraints' has on these breastfeeding mothers' lives (Stearns 2013, 361). When breastfeeding continues beyond infancy, these emotions become even more interesting since the embodied experiences can vary, influencing the mothers' lives in different ways. By giving a voice to these mothers, the article foregrounds information that is relevant for academic and public discussions. The article is attentive to two main research questions: what kind of embodied experiences and emotions do mothers who breastfeed long-term describe, and how does the duration of breastfeeding make a difference to their bodily experiences.

The following section explores extant feminist discussions about breastfeeding as an embodied practice, before going on to discuss the methods used and the analysis of the themes that emerged from the empirical data. I found four typical descriptions of experiences and I have named these as categories of the functional body, the tired body, the aesthetic body, and bodily pleasure.

\section{Feminist perspectives on breastfeeding, embodiment and sexuality}

It is interesting that researchers who identify as feminists have differing views on breastfeeding. As a feminist issue, breastfeeding can be analysed from several perspectives. Some authors have argued that compared with other mothering-related questions such as the medicalisation of childbirth, breastfeeding is a 'non-issue' for feminists (Wolf 2006, 397). Canadian researcher May Friedman commenting on breastfeeding rhetoric, has argued that the choice to breastfeed should be considered parallel to women's choice on abortion - no 
questions asked, or judgements made. She argues that there is much more to breastfeeding than the benefits to the child (Friedman, 2009). Yet, depending on the society they live in, not all women feel that they can actually choose whether to breastfeed an infant (see Andrews \& Knaak 2013, 104). The fears that biology may become destiny for women, and that those who do not breastfeed will be disrespected, remain essential concerns for feminists (Smith 2008). It is not easy to support women's right to breastfeed when there is a risk of returning to essentialist views on motherhood, or of women being shamed (see Taylor \& Wallace 2012a, 2012b). In this sense then, framing breastfeeding as the most essential part of being a good mother, is also problematic (Hausman 2004; Taylor \& Wallace 2012b) and can put unnecessary pressure on mothers.

Although there are many issues that have an effect on breastfeeding mothers' experiences, bodily expectations and norms are those that can elicit a conflictual experience; breasts are considered a visible part of femininity (Stearns 1999) yet breastfeeding is a bodily issue. The male ideal of the big-breasted woman may be one that is fulfilled when a woman's breasts are full of milk, but women are also expected to 'bounce back' after pregnancy and meet the norm of the fit female body (Nash 2015, 19). In her article on embodiment and maternity, Sally Johnson (2018) concluded that the ideal of western beauty does not allow mothers to take on a range of subject positions; rather it restricts them. However, the British mothers in her study resisted and (re)shaped these beauty norms in their notions of embodiment, while simultaneously suggesting that for a limited period of time, motherhood offered them protection from such expectations. Apart from aesthetics, the women described their bodies as strong. For example, one woman reshaped beauty norms by depicting her caesarean scar as a battle scar (Johnson 2018, 481; 483-485). There is evidence that Finnish women too are considered pragmatic in their choices of appearance and attitudes (Kinnunen 2010) and that might play some part here.

Breastfeeding - and long-term experiences of it - as an embodied practice can be viewed from many perspectives. Cindy Stearns, an American sociologist has described breastfeeding as an embodied element of parenting that is centred on mothers' bodies $(2013 ; 1999)$. She describes it as a 'time-consuming task' that may go on from short periods to many years (Stearns 2013, 362). Breastfeeding takes time, and some long-term breastfeeding mothers have found their experience of breastfeeding one which limited their bodily freedom (Dowling and Pontin, 2017). Since Finnish mothers have relatively long maternity leave, and 
live in a culture where breastfeeding is expected, they might experience this differently. Nevertheless, breastfeeding is an activity involving two bodies: the breastfeeding mother and the breastfed child whose bodies are repeatedly merged in a cooperative activity between two individuals (Gribble 2007). It is an inter-embodied experience where two bodies are conjoined (Lupton 2012). Stearns (2011) calls this a shift in embodied agency: the child also has embodied agency, since it can accept or reject the breast.

Adrienne Rich $(1991,285)$ famously wrote that every woman can be the "presiding genius of her own body'. However, the norms that define beauty standards as currency (Rice 2014), as well as those that define how long it is proper for a mother to breastfeed (e.g. ; Dowling 2013; Säilävaara 2016; Tomori et al. 2016), still exist and influence long-term breastfeeding women. Paige Hall Smith, an American researcher, has argued that there is a need for 'a feminist movement that fully incorporates women's needs as social beings'. This means defining the female body as a norm in the same way that the male body has been. She also writes of the 'labour of love' that breastfeeding could be if it were normalised in society. (Smith 2008, 6.)

The sexual connotation of breasts can complicate breastfeeding. Australian researcher Alison Bartlett $(2005,67)$ has written about 'the newer moral conservatism' concerning breastfeeding and sexuality, which in her view emerged in the 1990s. Bartlett's $(2005,67)$ idea of physiologically 'normal' sexual pleasure while breastfeeding is discussed here in relation to contemporary Finnish culture and motherhood, while also taking into account other embodied experiences that are described. The stigmatisation of breastfeeding, especially in relation to the sexual connotations of breasts, can make breastfeeding complicated, especially over the long-term (e.g. Tomori et al. 2016; Ward et al. 2006). Even with a baby, mothers are faced with people that are more used to a sexualised breast than a nursing one (Stearns 1999). As the child gets older, it has been found that people question whether it is necessary to breastfeed for so long, suggesting that mothers are doing it for their own pleasure (Dowling \& Brown 2013).

Discussions of the connection between sexual pleasure and breastfeeding often make reference to the infamous incident in the 1990s involving Karen Carter. Carter, a single mother in the US, had lost custody of her child after calling a helpline to ask about sexual pleasure while breastfeeding her two-year-old (Umansky 1998). This case has been a central 
reference point for much of the research on the relationship between breastfeeding and pleasure or sexuality (e.g. Bartlett 2002; Perlman 2019; Saha 2002; Stearns 1999). Carter's question sparked an investigation into sexual abuse and had long-term consequences. Perhaps as a result, some mothers have been reported (e.g. Stearns 1999, 318) to use language that refers to the sensation of breastfeeding as something happening 'outside their body'; by doing so they make it less sexual. Stearns (2013) has since raised the question of whether more women would continue breastfeeding for longer if public discussion concentrated more on the paradoxes involved in long-term breastfeeding and sexuality. With these previous findings and the context of my own research, the following explores the experiences of longterm breastfeeding mothers.

\section{Data and method}

The data was gathered by means of an open invitation to women to write about their experiences as long-term breastfeeding mothers. Data collection by email or letter was chosen because it allowed the mothers to answer in their own time and meant that geography would be no limit to participation ${ }^{1}$. The invitation was targeted at mothers who had breastfed for about two years or longer. It was published on a Facebook group for long-term breastfeeding mothers, on the discussion board of the Finnish Association for Breastfeeding Support, and in two online family magazines. It is possible that publishing the invitation exclusively online could have limited the sample and potentially influenced the findings. Still, I was pleased with the number of responses to my invitation to write. Some participants commented that they had heard about this research project from other mothers, so a snowball effect also worked in the recruitment.

The mothers were from different parts of Finland, represented different age groups and different levels of education. Most had a university or polytechnic degree, or were studying at the time of the data collection. The 39 women in the final sample ranged in age from 21 to 45 , more than half of whom were married or in a civil partnership, and lived with a partner and child or children. The mothers were not asked if they were currently working, but many described experiences with day-care personnel and breastfeeding after work, indicating that

\footnotetext{
${ }^{1}$ There is a strong tradition of using open invitations to write in Finland. For example, the Finnish Literature Society collects memories of various topics by open invitations to write.
} 
most of them were studying or working at the time. Some had little babies they were tandem breastfeeding with a toddler or a child.

All respondents identified themselves as long-term breastfeeding mothers. At the time of writing, all had been breastfeeding for over a year, and most for two years or slightly more. Four of the mothers had weaned their (long-term breastfed) child, and for them breastfeeding was a thing in the recent past or they were breastfeeding a baby at the time of the data collection. The age of the youngest child was one year and four months, whilst the oldest child described as actively breastfed was almost seven years old. The mothers had different reasons for breastfeeding long-term. Many described how they had 'just ended up' breastfeeding for longer than they had expected since it worked so well and gave them strong feelings of doing the right thing. Fewer than five of the mothers had planned to breastfeed as long as possible due to their parenting philosophy, which they called 'attachment parenting'. For them, this was described as more than just breastfeeding: they carried the baby in a sling, co-slept with them, and did not use diapers on their child. Many of the mothers wrote about love, and one described how long-term breastfeeding was 'Happiness with a capital H'. They described how breastfeeding helped with everyday life by giving them a break in otherwise busy schedules.

The invitation to participate gave instructions for the participants to follow. They were given questions to help them think about what to write, and encouraged to write as much as they wished about being a long-term breastfeeding mother. The length of the texts ranged from one to seven pages with an average of three pages. The mothers were encouraged to think about how they felt about long-term breastfeeding, about places and space related to breastfeeding and, if their perceptions had changed, how other significant people in their lives reacted. Three of the questions were particularly about embodiment: the participants were asked to think about how they found breastfeeding in relation to their body, whether they felt that breastfeeding had an effect on their well-being, and whether they felt pleasure while breastfeeding.

All the mothers were given a pseudonym, and any data that might reveal their identities was changed or removed from the text. All the extracts have been translated from Finnish to English. No ethical approval was required at the time of data collection. All intended participants were informed that the data would be used and stored in line with the ethical 
guidelines of the University of Jyväskylä. The participants were informed that no personal data or identification would be shared with others.

The data was subjected to inductive qualitative content analysis. This has been found to be a useful method for researching the sensitive subject of breastfeeding, as is suitable for analysing also large volumes of data (Elo \& Kyngäs 2008). The analysis began by structuring the data into content categories on the themes of embodiment that the mothers described. Repetitive themes started to form more clearly after the texts were divided into different subthemes. Eventually I found four themes in the writings: the functional body; the tired body; the aesthetic body; and pleasure related to the breastfeeding body. This method provided tools to analyse the data and then apply the results to the larger context of understanding mothering and breastfeeding mothers. The term 'mothering' will be used throughout this article, since it gives mothers agency and casts motherhood as something more than a pre-given form (Breengraad 2018, 317). In the sections below, the four themes are discussed in turn, in relation to both the findings from this study and the previous literature.

\section{Breastfeeding and the functional body}

The functional body was an essential feature in many writings. Eva, a single mother of one child, estimated that during four years of breastfeeding, her breasts had produced 1,500 to 2,000 litres of milk. In her description she rejoiced in her ability to breastfeed her child and that she was still doing so. She described that breastfeeding had made her see her body as functional rather than an object to be looked at; her appreciation of her own body evidently increasing after being pregnant, giving birth, and being able to breastfeed. Her text made it clear that she wanted to decide how to define her body, and not be defined by outsiders.

The idea of a functional body was also evident in Laura's story. Laura, a university-educated mother of two, described her experiences of embodiment using very rich language that captured the idea of functionality. She had breastfed her first child for two years and her second for almost five years; she described the birth of her first child, and her experiences, as follows: 
Breastfeeding had a crucial impact on my relationship with my body. Breasts... since my teenage years they had caused me some degree of suffering... those damned, embarrassing saggy bags were not connected or related to me, were even ugly. But when you add a hungry baby to this, you will immediately find meaning, even beauty. An absolutely crying out, profound meaning bigger than life, Life itself. And the relationship with a little baby, with whom I experienced for the first time in my life what Love is. When I had a chance to experience how, through me, the Universe loves itself, embracing not only this little sapling I'm holding but also the whole room, house, town, globe, galaxies... Love exploded through me and encompassed all the emotions in the world, even reaching the core of agony. [...] Closeness with your baby is something so different from closeness with your partner, even if you have been madly in love. For the first time, I could feel that my breasts were part of some wonderful, loving whole full of warmth, safety, nutrition... a flow of love from mother to child and back. I was so full of meaning and my place in the world was clear. I occupied that place with my entire body. Someone defined my true limits through my body, made me present in this world. (Laura, capital letters original)

In this extract, Laura wrote that her breasts had no positive meaning for her before breastfeeding, whereas now she felt her breasts belonged to her body, rather than being perceived as something external to her. She wrote that she found beauty in her breasts, after years of feeling that they were just loose parts. This sentiment arose in several of the women's writings. Iris Marion Young has described pregnancy as an awakening for many mothers in relation to embodiment, she describes it as "being thrown into awareness of one's body" (Young 2005, 51). In my data many mothers described being very aware of their embodiment. Mothers described how they had previously felt no connection with, or had just mixed feelings about, their breasts. However, since breastfeeding, they felt that their breasts had taken on new meanings. Paula, a mother of a two-year-old, wrote that she had felt ashamed of her breasts when she was young, but now they felt dear to her, something of her own.

Not all mothers wrote that their breastfeeding had always been functional and easy, indeed many wrote about the difficulties they had experienced, especially in the beginning. When these difficulties were mostly in the past, it seemed to reinforce belief in both their bodies and 
their breasts as parts of them, and this made mothers content. One example was Rosa, a mother of a two-and-a-half-year-old, who wrote about how her functional breasts had helped in her mothering. This was because Rosa was using equipment (such as a 'nursing supplementer'2) to help her lactate, since she had adopted her child and had not breastfed before. For her, breastfeeding had been very helpful in creating a relationship with the child. In their everyday life she had needed breaks (to relax while breastfeeding) and she described breastfeeding as working very well. Rosa gave an account of how she and her child had encountered many difficulties in making breastfeeding work but had still wanted to continue and had succeeded. She also described how her spouse, who had breastfed before, described problems with breastfeeding her biological child that were similar to hers, which made Rosa more confident in her breastfeeding.

It is evident that most of the mothers found new meaning for their bodies, and especially for their breasts, while breastfeeding.

I feel I can give my child something priceless; one is often too tired or otherwise unable to be exactly a perfect mother, and there are many things you cannot influence in your own child's life, but this is something I can do, I can breastfeed my child as long as she needs it. [...] Sometimes I feel it's my 'duty' to breastfeed because it goes well. (Isabella, breastfeeding a child aged two years and 11 months)

I feel it is fantastic that my body can produce food for my child! My child enjoys breastfeeding and skin contact a lot, and I am happy to offer her that. (Melissa, breastfeeding a child aged one year and nine months)

These excerpts illustrate how the meaningfulness of breastfeeding continued beyond babyhood (see Ryan et al. 2011). Isabella's description above highlighted well-functioning breastfeeding as something a mother is supposed to do - she calls it a 'duty'. She had breastfed her first-born for almost four years and was now breastfeeding her second child aged two years and 11 months. She described her decision to breastfeed long-term as one she was willing to work for.

\footnotetext{
${ }^{2}$ See La Leche League GB: https://www.laleche.org.uk/nursing-supplementers/
} 
Many of the writers emphasised that since their breastfeeding was going well and brought joy to the child, they were not planning to quit. The mothers made the point that because their child was no longer dependent exclusively on breast milk, it gave them more freedom. This opportunity to decide may also have contributed to the mothers feeling more in control of their own bodies. Nevertheless, being able to provide nutrition to one's child, and therefore having a strong feeling of being a 'good mum' was repeated in many descriptions. These findings are consistent with previous research on long-term breastfeeding (e.g. Dowling 2013), and they show that mothers describe their functional body while breastfeeding as rewarding.

\section{Breastfeeding and the tired body}

In their study of long-term breastfeeding mothers in the UK, Dowling and Pontin $(2017,66)$ found that participants felt 'tied' to their children and did not have the same 'personal space or bodily freedom' as mothers who did not breastfeed long-term. This was less apparent in my data, and few mothers referred to it. Mothers mostly wrote about how they had been physically tired, when breastfeeding took up more time and they had to wake up several times during the night. At the point when the child was no longer demanding to be breastfed regularly, and cared for all the time, mothers seemed to get more sleep and did not describe physical tiredness.

However, always being available to others came up in some writings, as did the participants' needs to have their bodies back to themselves without demands being placed on them. These descriptions are typical of mothers who have been breastfeeding for a long time (Dowling 2013). The child's decreasing dependency on the mother was also cited as a factor in not feeling so tired, since the child could cope without the mother for longer periods than a breastfed baby could. An aspect contributing to tiredness was that Finnish mothers typically work full-time. This applied to many of the mothers in this study, and they often breastfed after work, usually only once or a couple of times a day depending on the age of the child. Paula wrote about being tired after work: 
Of course I sometimes do feel that breastfeeding wears me out, for example when I get home tired and the child is crying for her mum and wants to be breastfed immediately (Paula, breastfeeding a two-year-old).

Maria, who was tandem breastfeeding an 18-month-old and a four-and-a-half-year-old, described feeling too tired to breastfeed. The continuous demand that she should be available and ready to give milk made her want to hide. However, she explained that this did not happen more than 'once a week'.

The question of physical tiredness arose when mothers described how breastfeeding affected their sleep. Although some described being able to sleep while breastfeeding and sharing the bed with their child, not all were able to do so. Most had already stopped breastfeeding at night, but some like Emma, felt it was tiring:

The downside of breastfeeding at night is that I have not had a solid night's sleep in two years, and little by little I am getting tired (Emma, breastfeeding a twoyear-old).

Conversely, breastfeeding was also described by some as helping with sleep. Mia, mother to a two-and-a-half-year-old, described how breastfeeding helped her sleep 'excellently'. The experiences of tiredness seemed to be either limited, or more related to other things, such as not going to bed early enough.

In these writings, being tired was discussed through embodied experiences. The positive functionality was shadowed by being physically and emotionally tired. However, tiredness was not discussed that much, and was often described as something 'in the past' that the mother had already overcome.

\section{Breastfeeding and the aesthetic body}

The mothers described not only aesthetic changes, but also changes in their attitudes towards their bodies while breastfeeding; many wrote of how they were more accepting of their own bodies. With regard to normative beauty ideals, mothers described their breasts with a sense of humour. They described them after pregnancy and breastfeeding as looking tatty or like 
potholders; Jasmin, breastfeeding a child aged one year and four months, wrote that her 'boobs are not so cool anymore. Ha ha ha!' Nevertheless, the mothers who described their breasts as 'drooping' also said that it did not matter. Sara, who was tandem breastfeeding two children, aged three years and three months and six years and ten months, wrote 'both my children like my saggy breasts really a lot', while Irene described her own breasts as 'stretched but still beautiful' after breastfeeding for almost two years.

Stearns' (1999) notion of breasts as the visible part of femininity came up in the mothers' discussions about the shape and size of their breasts. In Paula's account of how her relationship with her own body had improved over the years, she explained this as something to do with ageing, but also related to breastfeeding:

Breastfeeding has improved my relationship with my own body. I feel more feminine. When I was younger, I was ashamed of my small breasts, but no longer - now my breasts feel precious and personal (Paula, breastfeeding a two-yearold).

Mothers used humour to describe changes in their breasts and their bodies, stating that they felt beauty norms no longer mattered to them. Still, they were aware of the assumption that breastfeeding could 'ruin' their breasts (see also Wolf 2006).

The relationship between breastfeeding and my body. Not significant at all, or actually, yes, when I think more about it. My breasts already started to sag during pregnancy; with my big belly and saggy breasts I looked like a prehistoric Mother Earth statue. Not breastfeeding would in no way have rescued me from that. In fact, from the perspective of the Western beauty/sex appeal ideal, my breasts were at their most beautiful during the first three months, when they were genuinely full of milk and swollen. I looked just like Pamela Anderson - DD - if you don't count my excessive stomach skin. Now all that's left are the empty skin bags (Alma, breastfeeding a child aged one year and seven months).

My breasts already 'sagged' when I was about 20, long before pregnancy and this breastfeeding. And even if it's the breastfeeding that takes my breasts further away from the superficial female ideal presented in today's media, I would still 
choose to breastfeed, because I find it so important, for rational and emotional reasons (Melissa, breastfeeding a child aged one year and nine months).

The mothers in my data also did not say much about needing to 'bounce back' to their prepregnancy weight (see Nash 2015, 19). This too may be related to time, since they were no longer new mothers. About 25 percent of the mothers said that breastfeeding helped them to keep their body weight low, while Jasmin even wrote that she had lost 'too much weight' after breastfeeding for almost two years.

The mothers knew that there were beauty standards and norms that they as women were supposed to fulfil. However, they did not completely comply with these norms, and still felt good about their bodies. Accepting one's own body after pregnancy and childbirth, including any possible weight changes, was discussed in their writings. They wrote that they were more accepting of their own bodies, even if they did not fit conventional beauty norms. Mothering and breastfeeding somewhat protected these women from 'superficial' beauty ideals, as Melissa stated above. In contrast with Johnson's (2018) UK study, where mothers reported a limit to how long mothering protected women from getting back into shape and returning to the normative body, the mothers in my sample were still breastfeeding, which might explain the difference. It is possible that the mothers in my study were balancing the pressures of normative beauty norms with humour since they were 'providing the best nutrition for the child', as several of them put it. They also wrote that their body was to be viewed as more than an object, and that they no longer cared or got stressed about beauty norms, as their children described their mothers' breasts and bodies as beautiful and perfect.

\section{Breastfeeding and bodily pleasure}

The Finnish word mielihyvä (pleasure, enjoyment), which was used in the invitation to participate in the research project, can also relate to sexual pleasure. The intention was to ask about all kinds of pleasure, but many of the mothers seemed to interpret this as only relating to sexual pleasure, and therefore almost a quarter of the mothers emphasised that there was no sexual pleasure in long-term breastfeeding. Lisa for example, who was breastfeeding a child aged one year and ten months, wrote that she had not had any 'sexual vibes on breastfeeding even if some seem to think so'. Mothers used comments such as 'nothing sexual', and some arguably ignored this question, writing nothing about any kind of pleasure 
(see also Perlman 2019, 133). When pleasure was brought up, they would describe feeling close to their child, emotional pleasure, and the pleasure of doing the right thing for their child. Laura's description was a little different, however, as she wrote about an experience close to sexual pleasure:

Over the course of my long breastfeeding years, breastfeeding - along with being difficult at the beginning - has been wonderful, intimate, enjoyable, but also quite mundane and ordinary. I have also enjoyed it myself. I remember having realised in my first breastfeeding year that the hormones that churn around when you are breastfeeding are really the same 'love hormones' that play a role when one falls in love, makes love and gives birth, and also create intimacy, a bond and protection between family members. The thought is potentially confusing, of course. A few times, when breastfeeding, I have felt pleasure that is closely related to sexual pleasure. I have not let this disturb me, even though the thought can actually be rather close to some limits of propriety. I have explained it to myself in terms of biology and hormones as well as the purposefulness of nature (Laura).

In this extract, Laura explains how she rationalised her pleasure in terms of hormones and nature. Her account seems to capture the problem of combining sexual pleasure and breastfeeding, although it differs markedly from other descriptions. The 'naturalness' of feeling good while breastfeeding also came up in one other text. Sara wrote that 'biologically, it is supposed to be pleasant!' and said that therefore she had felt both pleasant and unpleasant embodied experiences while breastfeeding. These two examples refer to the biological aspect of breastfeeding, meaning that they described breastfeeding as 'biological' or 'natural', making it a mammalian thing.

It was interesting that so many mothers emphasised that breastfeeding had nothing to do with sexuality. In the UK, women are reportedly aware of the negativity in the media about longterm breastfeeding and the way it is represented as 'sexually inappropriate and/or psychologically maladjusted' (Newman \& Williamson 2018, 232). The women in my research also referred to public discussions mainly online, and Eva also mentioned how the word 'incest' is typically employed in anonymous discussions. They seemed to be aware that other people could find long-term breastfeeding 'a weird and suspicious thing to do' (Olga, 
breastfeeding a five-year-old) and that 'some consider it perverse' (Helena, whose child was weaned at a little over three years old). A few mothers wrote that their partners were not allowed to touch their breasts because they 'belonged' to the child. Alma, however, wrote that she did not get any sexual pleasure while breastfeeding, but she did feel pleasure when her partner touched her breasts now that they were more sensitive to touch.

The question about pleasure caused mixed feelings. Even if many mothers did not emphasise the relationship to sexuality, they did describe emotional pleasure, feelings of being a good mother, and/or doing the right thing. Moreover, they denied any sexual connotations. It is understandable that they would do so, not only for fear of being judged (Umansky 1998), but also because mothering and sexuality are culturally distant phenomena. The evidence suggests that the mothers received the definition of long-term breastfeeding as a sexual act more from the outside, meaning they had to defend their breastfeeding to outsiders. The mothers themselves defined long-term breastfeeding as giving them emotional rather than sexual pleasure.

\section{Conclusion}

This article has analysed the embodied experiences of long-term breastfeeding mothers. In their writings, the mothers connected breastfeeding long-term to different embodied experiences that they described as both emotionally rewarding and challenging. The embodied experiences were linked to a mothers' right to her own body, to beauty norms and to bodily pleasure. These experiences were discussed through functionality and tiredness, aesthetics and bodily pleasure. The functional body was often described as more important than either an aesthetic body (narrowly defined) or fulfilling beauty norms and expectations. The mothers expressed that they felt strong because their bodies were able to function; to produce milk. They also stated that being able to breastfeed made them more content in their bodies. Even with conflicted feelings and experiences, long-term breastfeeding was portrayed as rewarding and worth doing. Pleasure in relation to breastfeeding was discussed but was usually emphasised as not sexual; rather it was related to emotional or bonding pleasure.

Fourth-wave feminist campaigns such as "Free The Nipple" have been analysed as women taking control of the representations of their bodies. Women are reclaiming the female body by refusing the sexualized and objectified representations of women. (Matich et al. 2018.) I 
argue that these long-term breastfeeding mothers are also taking control in refusing to "bounce back" and expressing also positive embodied experiences. While it is possible that only mothers who have positive experiences are likely to participate in this type of research, the richness and depth of my research data convinced me, on the basis that most of the mothers were unafraid to express both positive and conflicted emotions and experiences.

The participating mothers had all breastfed for more than a year, some for many years. Nevertheless, some embodied experiences may be similar no matter how long the mother breastfeeds (Schmied \& Barclay 1999). Mothers who have breastfed for longer have a uniquely longer-term perspective on changes in their bodies, and on societal expectations about how long it is appropriate to breastfeed. One interesting finding that contrasts with the extant research was the emphasis the mothers placed on the functionality of their bodies, which made them useful and important, and even made their relationship with their bodies more positive. The fact that their bodies and breasts no longer conformed to existing beauty norms, but were experienced as functional, was commonly reported as compensation for their tiredness. There are culturally shared stereotypes of the functional Finnish woman in relation to her appearance and attitude towards beauty norms (Kinnunen 2010) and perhaps this practicality comes across here in relation to breastfeeding. Mothers described how they were pleased to be able to produce milk for their children and therefore felt proud of their bodies, making them more acquiescent to aesthetic changes in their bodies and breasts.

Being tired - or not as tired as they had been when their child was still an infant - was discussed in their writings. Participants stated that they were tired of (still) having to be available; an experience common to mothers of young babies. Nevertheless, mothers expressed that the decision to breastfeed long-term was theirs, and easier compared to feeling tied down when mothering an infant. These mothers had more choice and freedom in their everyday lives. The cultural ideas of attachment parenting and mothering might also have some affect here. There is a continuing contradiction for mothers and especially feminist mothers who might feel tied to the child (Dowling \& Pontin 2017), yet empowered by their breastfeeding (Blum 1993) and simultaneously subject to the pressure of being an independent woman (Schmied \& Lupton 2001).

These long-term breastfeeding mothers knew the beauty norms and standards their bodies and breasts were expected to fulfil but they were still, to some extent, able to resist them (see 
Johnson 2018). These norms were perceived as strict, and many resorted to humour while trying to cope with the weight of expectation. The use of humour shows how strong these norms are, and how mothers in part accepted them, rather than strongly resisted them. However, being able to produce 'the best nutrition for the child' was often reflected as surpassing the need to fulfil the expectations that women face regarding their bodies. The fact that many of the mothers were aware that others saw long-term breastfeeding as unnecessary, made it more interesting that many still preferred breastmilk as the 'best nutrition' for their child. Recommendations to breastfeed beyond infancy do exist but they are not largely promoted or supported by healthcare professionals (THL 2016; Säilävaara 2016).

With regard to breastfeeding children over one year old, and who are no longer dependent on breastfeeding for nutrition, concerns have often been expressed about mothers' potential pleasure, and whether there might be a hidden sexual agenda in breastfeeding (Dowling \& Brown 2013). Bartlett's (2005) juxtaposition of sexual pleasure with breastfeeding was not apparent in this data: those that expressed their opinion referred to breastfeeding as sometimes pleasurable, but on an emotional rather than a sexual level. In a way, these women were also taking part in desexualising their nursing breasts (Young 2005). I argue that this has to do with public discussion where long-term breastfeeding is interpreted as somehow inappropriate or even perverted (Norwood \& Turner 2014), but also to the strong cultural norm of breastfeeding at most for one year.

It is possible that the participants disregarded negative embodied experiences because they were at liberty to choose what to write and because breastfeeding for longer had been their choice. For some, long-term breastfeeding was part of a parenting philosophy, whilst for others, it just worked well and was therefore continued; either way, it was a path they chose. Since long-term breastfeeding does not conform to the norm and the mothers were committed to defending their choices, it might be challenging for some mothers to express negative feelings about their experiences of it. Many of them had received negative comments from outsiders, so they may have chosen not to write so much about these experiences in order to avoid giving these people more spurious "proof" of how long-term breastfeeding is undesirable.

Young has pointed how "patriarchal divisions seek to repress and silence" women's experiences but that these divisions can be challenged (Young 2005, 89). My analysis is part 
of this challenging; as an attempt to tell about the embodied experiences of long-term breastfeeding mothers, it takes part in giving a voice to these women. Cultural differences in breastfeeding practices make these findings particular to the Finnish context and not necessarily transferable to other settings. Compared with the UK (Dowling \& Pontin 2017), for example, Finnish women breastfeed more, and for longer. However, in both these countries, long-term breastfeeding defies the cultural norm. From a feminist point of view, these mothers lived in a society full of expectations and demands on them and on the female body. Feminist views on breastfeeding and mothering need to evolve even further, and the question of embodiment needs to be central to research on mothering.

\section{Acknowledgements}

The author would like to express her thanks to UWE Bristol, UK and especially to Dr. Sally Dowling; the participants who took part in the research and the reviewers for their helpful comments.

\section{References}

Andrews, T. \& Knaak, S. (2013). Medicalized mothering: experiences with breastfeeding in Canada and Norway. The Sociological Review, 61:1, 88-110.

Bartlett, A. (2002). Breastfeeding as headwork: corporeal feminism and meanings for breastfeeding. Women's Studies International Forum, 25:3, 373-382.

Bartlett, A. (2005). Maternal sexuality and breastfeeding. Sex Education, 5:1, 67-77.

Blum, L. M. (1993). Mothers, babies, and breastfeeding in late capitalist America: The shifting contexts of feminist theory. Feminist Studies, 19:2, 290-311.

Breengaard, M. H. (2018). Feeding mothers' love: stories of breastfeeding and mothering in urban China. NORA: Nordic Journal of Feminist and Gender Research, 26:4, 313-330.

Dowling, S. (2013). Exploring the experiences of women who breastfeed long-term. PhD thesis. Bristol: University of the West of England.

Dowling, S. \& Brown, A. (2013). An exploration of the experiences of mothers who breastfeed long-term: what are the issues and why does it matter? Breastfeeding Medicine, 8:1, 45-52. 
Dowling, S. \& Pontin, D. (2017). Using liminality to understand mothers' experiences of long-term breastfeeding: 'betwixt and between', and 'matter out of place'. Health, 21:1, 57-75.

Elo, S. \& Kyngäs, H. (2008). The qualitative content analysis process. Journal of Advanced Nursing, 62:1, 107-115.

Faircloth, C. (2013). "What feels right": Affect, emotion, and the limitations of infant-feeding policy. Journal of Women, Politics \& Policy, 34:4, 345-358.

Friedman, M. (2009). For whom is breast best? Thoughts on breastfeeding, feminism and ambivalence. Journal of the Association for Research on Mothering, 11:1, 2635 .

Gribble, K. (2007). 'As good as chocolate' and 'better than ice cream': how toddler, and older, breastfeeders experience breastfeeding. Early Child Development and Care, 179:8, 1067-1082.

Hakulinen, T. \& Otronen, K. (2017). Toimintaohjelman tarkoitus ja tavoitteet [Action programme's meaning and aims]. In T. Hakulinen, K. Otronen \& M. Kuronen (Eds), Kansallinen imetyksen edistämisen toimintaohjelma vuosille 2018-2022 [National Action Programme on Breastfeeding Promotion 2018-2022]. Helsinki: THL, 17-18 Retrieved from https://www.julkari.fi/bitstream/handle/10024/135535/Ohjaus\%20242017\%20n etti\%202.1.pdf?sequence=1

Hausman, B. (2004). The feminist politics of breastfeeding. Australian Feminist Studies, $19: 45,273-285$.

Johnson, S. (2018). 'I see my section scar like a battle scar': the ongoing embodied subjectivity of maternity. Feminism \& Psychology, 28:4, 470-487.

Kinnunen, T. (2010). 'A second youth': pursuing happiness and respectability through cosmetic surgery in Finland. Sociology of Health \& Illness, 32:2, 258-271

Lupton, D. (2012). Infant embodiment and interembodiment: a review of sociocultural perspectives. Childhood, 20:1, 37-50.

Matich, M., Ashman, R. \& Parsons, E. (2019) \#freethenipple - digital activism and embodiment in the contemporary feminist movement. Consumption Markets \& Culture, 22:4, 337-362.

Nash, M. (2015). Shapes of motherhood: exploring postnatal body image through photographs. Journal of Gender Studies, 24:1, 18-37. 
Newman, K. L. \& Williamson, I. R. (2018). 'Why aren’t you stopping now?!' Exploring accounts of white women breastfeeding beyond six months in the east of England. Appetite, 129, 228-235.

Norwood , \& Turner, P.K. (2013) The Breast Is (Always) for Sex: Breastfeeding Discourse in Response to May 21, 2012 TIME Magazine Cover. Qualitative Research Reports in Communication, 14:1, 79-86.

Perlman, L. (2019) Breastfeeding and Female Sexuality. Psychoanalytic Review, 106:2, 131148.

Rice, C. (2014). Becoming Women: The Embodied Self in Image Culture. Toronto: University of Toronto Press.

Rich, A. (1991). Of Woman Born: Motherhood as Experience and Institution. London: Virago.

Ryan, K., Todres, L. \& Alexander, J. (2011). Calling, permission, and fulfillment: the interembodied experience of breastfeeding. Qualitative Health Research, 21:6, $731-742$.

Saha, P. (2002). Breastfeeding and sexuality: professional advice literature from the 1970s to the present. Health Education \& Behavior, 29:1, 61-72.

Schmied, V. \& Barclay, L. (1999). Connection and pleasure, disruption and distress: women's experiences of breastfeeding. Journal of Human Lactation, 15:4, 325334.

Schmied, V. \& Lupton, D. (2001). Blurring the boundaries: breastfeeding and maternal subjectivity. Sociology of Health \& Illness, 23:2, 234-250.

Smith, P. H. (2008). 'Is it just so my right?' Women repossessing breastfeeding. International Breastfeeding Journal, 3:12.

Stearns, C. A. (1999). Breastfeeding and the good maternal body. Gender \& Society, 13:3, $308-325$.

Stearns, C. A. (2011). Cautionary tales about extended breastfeeding and weaning. Health Care for Women International, 32:6, 538-554.

Stearns, C. A. (2013). The embodied practices of breastfeeding: implications for research and policy. Journal of Women, Politics \& Policy, 34:4, 359-370.

Säilävaara, J. (2016). Imettämässä kaapissa? Pitkään imettäneet äidit ja normatiiviset tilat. Sukupuolentutkimus, 29:2, 7-20.

Taylor, E. N. \& Wallace, L. E. (2012a). Feminist breastfeeding promotion and the problem of guilt. In P. H. Smith, B. L Hausman \& M. H. Labbok (Eds), Beyond Health, 
Beyond Choice: Breastfeeding Constraints and Realities. New Brunswick: Rutgers University Press, 193-202.

Taylor, E. N. \& Wallace, L. E. (2012b). For shame: feminism, breastfeeding advocacy, and maternal guilt. Hypatia, 27:1, 76-98.

THL (2016). Eating Together: Food Recommendations for Families with Children. Helsinki: THL. Retrieved from http://www.julkari.fi/bitstream/handle/10024/130435/URN_ISBN_978-952302-626-1.pdf? sequence=1

THL (2018). The reconciliation of work and family-life. Retrieved from https://thl.fi/en/web/gender-equality/gender-equality-in-finland/wellbeing/thereconciliation-of-work-and-family-life

Tomori, C., Palmquist, A. E. L. \& Dowling, S. (2016). Contested moral landscapes: negotiating breastfeeding stigma in breastmilk sharing, nighttime breastfeeding, and long-term breastfeeding in the US and the UK. Social Science and Medicine, 168, 178-185.

Umansky, L. (1998). Breastfeeding in the 1990s: the Karen Carter Case and the politics of maternal sexuality. In M. Ladd-Taylor \& L. Umansky (Eds), 'Bad' Mothers: The Politics of Blame in Twentieth-Century America. New York: New York University Press, 299-309.

Ward, L. M., Merriwether, A. \& Caruthers, A. (2006). Breasts are for men: media, masculinity ideologies, and men's beliefs about women's bodies. Sex Roles, 55:9-10, 703-714.

Wolf, J. H. (2006). What feminists can do for breastfeeding and what breastfeeding can do for feminists. Signs, 31:2, 397-424.

Young, Iris Marion. (2005). On female body experience: "Throwing like a girl" and other essays. New York: Oxford University Press. 